\title{
Chronic disease and infant nutrition: is it significant to public health?
}

\author{
Julie P Smith* and Peta J Harvey \\ Australian Centre for Economic Research on Health, College of Medicine and Health Sciences, Australian \\ National University, Canberra ACT 0200, Australia
}

Submitted 9 October 2009: Accepted 1 June 2010: First published online 13 July 2010

\begin{abstract}
Objective: To assess the public health significance of premature weaning of infants from breast milk on later-life risk of chronic illness.

Design: A review and summary of recent meta-analyses of studies linking premature weaning from breast milk with later-life chronic disease risk is presented followed by an estimation of the approximate exposure in a developed Western country, based on historical breast-feeding prevalence data for Australia since 1927. The population-attributable proportion of chronic disease associated with current patterns of artificial feeding in infancy is estimated.

Results: After adjustment for major confounding variables, current research suggests that the risks of chronic disease are 30-200\% higher in those who were not breast-fed compared to those who were breast-fed in infancy. Exposure to premature weaning ranges from $20 \%$ to $90 \%$ in post-World War II age cohorts. Overall, the attributable proportion of chronic disease in the population is estimated at $6-24 \%$ for a $30 \%$ exposure to premature weaning.

Conclusions: Breast-feeding is of public health significance in preventing chronic disease. There is a small but consistent effect of premature weaning from breast milk in increasing later-life chronic disease risk. Risk exposure in the Australian population is substantial. Approximately $90 \%$ of current 35-45-year-olds were weaned from breast-feeding by 6 months of age. Encouraging greater duration and exclusivity of breast-feeding is a potential avenue for reducing future chronic disease burden and health system costs.
\end{abstract}

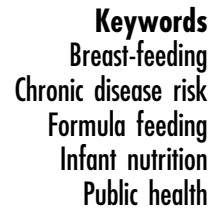

Keywords onic disease risk Formula feeding Public health
In recent years, governments around the world have focused on the rising burden of chronic disease and its growing impact on health system costs. Nutrition and diet-related activities are recognized elements of proposed national and international risk reduction strategies for chronic disease. In the past decade, several major studies have drawn the link between infant feeding and later-life chronic disease ${ }^{(1,2)}$.

The higher risk of infectious illnesses and the immunological vulnerability of non-breast-fed infants is well known ${ }^{(3)}$. Evidence has recently been accumulating on associated increases in both maternal and infant risk for a number of chronic diseases in later life. These include obesity $^{(4,5)}$, diabetes ${ }^{(6)}$, CVD risk including high blood pressure $^{(7)}$, as well as some childhood cancers ${ }^{(8)}$, breast cancer in the mother ${ }^{(9)}$ and a range of chronic digestive (ulcerative colitis, Crohn's disease and coeliac disease $)^{(10,11)}$ and allergic diseases, including asthma ${ }^{(12-14)}$. In 2006 , following a review of potential prevention strategies $^{(15)}$, the European Council of Ministers endorsed breast-feeding as a key action area for addressing obesity ${ }^{(16)}$.
The World Cancer Research Fund Expert Report has recommended that mothers breast-feed and that children be breast-fed to reduce their risk of cancer ${ }^{(17)}$. In Australia, a key implementation action area in the National Chronic Diseases Strategy ${ }^{(18)}$ is to increase the rates of full breastfeeding at 6 months. The strategy regards the need to start early to ensure success in preventative measures and concludes:

Full breastfeeding for at least the first six months of life offers considerable health benefits to infants, and potential benefits over the entire lifespan of the individual. Breast fed infants are less likely to develop high blood pressure, some infectious diseases, and some diet related chronic diseases later in life ${ }^{(18)}$.

Few populations around the world achieve the WHO recommendation for infant feeding, i.e. for exclusive breastfeedingt to 6 months with continued breast-feeding along

$\uparrow$ The definition of exclusive breast-feeding is receiving only breast milk from his/her mother or a wet nurse, or expressed breast milk, and no 
with appropriate complementary foods to 2 years and beyond $^{(19)}$. For example, in Australia, only about half the infants are still breast-feeding at 6 months ${ }^{(20)}$. In situations where a large proportion of the population is exposed, public health implications of even small risks can be striking $^{(21)}$.

Infant feeding practices are determined by a wide range of cultural, social and economic factors, not just potential health impacts. Opinions differ on whether breast-feeding saves time and work for mothers, but there is evidence that breast-fed infants spend more time interacting with their mothers, including on feeding, and that employment is associated with reduced breast-feeding ${ }^{(22-26)}$. Indeed, the health promotion model of breast-feeding has been criticized because of dilemmas for maternal employment ${ }^{(27-30)}$. Media attention focuses intensely on any studies purporting to challenge the importance of breast-feeding ${ }^{(31-33)}$ and questions have been raised about promoting breast-feeding as environmental pollutants can be measured in breast milk ${ }^{(34-36)}$.

The aim of the present study is to provide a summary assessment of the public health significance of premature weaning of infants from breast milk and breast-feeding for the prevalence of chronic illness in the Australian population.

\section{Method}

The objective of the present study is to estimate the population-attributable proportion of chronic disease associated with artificial feeding in infancy in a developed country such as Australia in order to evaluate the public health significance of breast-feeding for chronic disease prevention.

First, we review evidence from recent meta-analyses on links between lack of breast-feeding in infancy and later-life chronic disease. We identify those chronic diseases with evidence supporting possible or probable links between artificial feeding and later-life chronic disease and illness: obesity, type 1 and type 2 diabetes, CVD, asthma, coeliac disease, inflammatory bowel disease and childhood cancer. We conducted a Medline search (1966-2007) to identify relevant meta-analyses and hand-searched cited articles for other studies. We reviewed these meta-analyses to obtain the most reliable and recent estimates of OR and relative risk. In most cases, there were only one or two metaanalyses. We prioritized results from higher-quality studies if ambiguity existed between meta-analyses and, where possible, used results that reflected adjustment for important potential confounding sociodemographic, economic and anthropometric variables.

Second, we reviewed evidence on risk exposure levels, using long-term historical data on breast-feeding rates that were collected at child health clinics in Victoria, Australia,

(footnote continued)

other liquids or solids with the exception of drops or syrups consisting of vitamins, mineral supplements or medicines. since the 1920s. As ethical considerations limited experimental studies in this field, we also provided a commentary on methodological issues currently encountered in breastfeeding research and plausible causal mechanisms.

It is not well established that the degree of exposure to artificial feeding is associated with heightened later chronic illness risk, because existing research uses a variety of definitions of exposure to premature weaning to compare chronic disease prevalence in breast-fed with non-breast-fed groups. We therefore estimate the attributable proportion of chronic disease incidence in Australia for six scenarios regarding the extent of earlylife exposure to artificial feeding. These estimates correspond to the potential health burden for three distinct historical cohorts and for feeding status at either 6 months or at hospital discharge. This approach allows us to assess the extent of chronic disease that is potentially avoided by increased breast-feeding for the population as a whole in a developed country like Australia in a manner that allows for uncertainty arising from existing limitations in breast-feeding research.

\section{Results}

\section{Relative risk estimates}

Our search identified fourteen meta-analyses, which provided estimates of pooled adjusted relative risks or OR for eight chronic disease conditions. Table 1 presents a summary of results of these meta-analyses. Our preferred relative risk estimates and the studies they were drawn from are highlighted in the table. Below we discuss the various meta-analyses and the strengths of those that are selected as the basis of our preferred relative risk estimates.

\section{Obesity}

There have been five recent meta-analyses in which the outcome was the risk of obesity or overweight ${ }^{(4,5,37-39)}$. The relative risk for the artificially fed group was found to be $11-28 \%$ higher than for breast-fed infants. Our preferred estimate is that of Horta et $a l^{(38)}$, which included the largest number of studies, including the most recent one. The authors reported that controlling for confounding by socio-economic status and parental anthropometry did not modify the effect of breast-feeding. A dose-dependent relationship was evident in two of the meta-analyses ${ }^{(5,37)}$. For example, Harder et al.'s ${ }^{(37)}$ metaanalysis of seventeen different studies measuring the duration of breast-feeding (121000 participants) found that the probability of overweight/obesity in later life was increased by $4 \%$ for each month of not breast-feeding.

\section{Diabetes}

The risk of type 1 diabetes among different infant feeding groups has been examined by two meta-analyses ${ }^{(40,41)}$. Norris and Scott ${ }^{(41)}$ were concerned with the confounding 
Table 1 Results from meta-analyses of epidemiological studies on infant feeding and later disease risk*

\begin{tabular}{|c|c|c|c|}
\hline Chronic disease & $\mathrm{RRt}$ for artificially fed infants & Confidence limits & Reference \\
\hline \multirow[t]{5}{*}{ Obesity } & $1 \cdot 28$ & $1 \cdot 15,1 \cdot 43$ & Arenz et al. ${ }^{(4)}$ \\
\hline & $1 \cdot 15$ & $1 \cdot 12,1 \cdot 18$ & Owen et al. ${ }^{(5)}$ \\
\hline & $1 \cdot 23$ & $1 \cdot 14,1 \cdot 35$ & Harder et al. ${ }^{(37)}$ \\
\hline & $1 \cdot 11$ & - & Van Rossum et al. ${ }^{(39)}$ \\
\hline & $1 \cdot 28$ & $1 \cdot 19,1 \cdot 39$ & Horta et al. ${ }^{(38)}$ \\
\hline \multirow[t]{2}{*}{ Diabetes (type 1) } & $1 \cdot 43$ & $1 \cdot 15,1 \cdot 77$ & Gerstein $^{(40)}$ \\
\hline & $1 \cdot 23$ & $1 \cdot 12,1 \cdot 35$ & Norris and $\mathrm{Scott}^{(41)}$ \\
\hline \multirow[t]{2}{*}{ Diabetes (type 2) } & 1.64 & $1 \cdot 18,2 \cdot 27$ & Owen et al. ${ }^{(6)}$ \\
\hline & 1.59 & $1 \cdot 12,2 \cdot 22$ & Horta et al. ${ }^{(38)}$ \\
\hline \multicolumn{4}{|l|}{ Heart, stroke and vascular disease } \\
\hline Hypertension & $\sim 1 \cdot 20$ & $\mathrm{~N} / \mathrm{A}$ & Martin et al. ${ }^{(7)}$ \\
\hline $\mathrm{CHD}$ & $\sim 1.06$ & & \\
\hline Strokes/ischaemic attacks & $\sim 1 \cdot 18$ & & \\
\hline \multirow[t]{2}{*}{ Asthma } & $1 \cdot 37$ & $1 \cdot 19,1 \cdot 61$ & Gdalevich et al. $^{(13)}$ \\
\hline & $1 \cdot 37$ & $1.09,1.69$ & Ip et al. ${ }^{(43)}$ \\
\hline Coeliac disease & $2 \cdot 08$ & $1 \cdot 69,2 \cdot 5$ & Akobeng et al. ${ }^{(10)}$ \\
\hline \multicolumn{4}{|l|}{ Inflammatory bowel disease } \\
\hline Crohn's disease & $1 \cdot 49$ & $1 \cdot 16,1 \cdot 92$ & Klement et al. ${ }^{(44)}$ \\
\hline Ulcerative colitis & $1 \cdot 30$ & $1.04,1.65$ & \\
\hline \multicolumn{4}{|l|}{ Childhood cancer } \\
\hline Acute lymphocytic leukaemia & $1 \cdot 32$ & $1 \cdot 19,1 \cdot 47$ & Kwan et al. ${ }^{(45)}$ \\
\hline Acute myelogenous leukaemia & $1 \cdot 18$ & $1.02,1.37$ & \\
\hline All childhood cancers & $1 \cdot 28$ & $1.01,1.64$ & Martin et al. ${ }^{(8)}$ \\
\hline Childhood leukaemia & $1 \cdot 12$ & $1.06,1.20$ & \\
\hline Acute lymphocytic leukaemia & $1 \cdot 25$ & $1 \cdot 10,1 \cdot 41$ & Ip et al. ${ }^{(43)}$ \\
\hline
\end{tabular}

$\mathrm{RR}$, relative risk; N/A, not applicable.

* Shading represents our preferred estimates for use in later calculations.

tAssuming RR approximates the inverse of the OR, where OR represents the protective effect of breast-feeding and RR represents the risk of artificial feeding. ¥Confidence limits are based on $95 \% \mathrm{Cl}$ of OR.

issue of recall bias in their meta-analysis of seventeen casecontrol studies, whereas Gerstein ${ }^{(40)}$ assessed four casecontrol studies which met the high-quality methodological criteria. Commonly considered confounders in these studies were family history of type 1 diabetes, neonatal illness, maternal age at birth, birth order, maternal/parental education and type of delivery. The present study combines both adjusted and unadjusted OR to estimate a relative risk of 1.43 for those artificially fed younger than 3 months of age compared to those who experienced any breast-feeding beyond 3 months ${ }^{(40)}$.

Two meta-analyses of studies on the risk of type 2 diabetes were identified. Owen et al. ${ }^{(6)}$ and Horta et al. ${ }^{(38)}$ covered the same studies and obtained similar estimates. However, as the earlier review included a larger number of studies, this meta-analysis is preferred. This review of seven studies included 76744 infants. A dose-dependent effect of exposure to artificial feeding was found by both the research groups ${ }^{(6,38)}$. Owen et al. noted that maternal social class, maternal weight and low birth weight could influence both the likelihood of breast-feeding and the risk of later diabetes. However, adjustment for such confounders had little effect on the association between breast-feeding and risk of diabetes.

\section{Heart, stroke and vascular disease}

Two studies have examined the relationship between infant feeding practices and blood pressure as an indicator of later-life cardiovascular health ${ }^{(7,42)}$. The meta-analysis by Martin et $a l .{ }^{(7)}$ includes data on extra infants from additional studies. It reports that reductions in population mean blood pressure levels of the magnitude found, if causal, 'could reduce the prevalence of hypertension by up to 17 percent, the number of coronary heart disease events by 6 percent, and strokes and transient ischemic attacks by 15 percent' (p. 24). This was not influenced by adjustment for accelerated postnatal weight gain, although residual confounding for socio-economic factors was possible. We have estimated the relative risks for hypertension, CHD and strokes/ischaemic attacks based upon these percentages.

\section{Asthma}

Two meta-analyses have examined the effects of infant feeding on childhood risk of asthma and have concluded that lack of breast-feeding is associated with an increased risk of developing asthma ${ }^{(13,43)}$. This association is stronger for those infants with a family history of asthma. Data presented in Table 1 show the risk of developing asthma for artificially fed infants without a family history of asthma.

Ip et al. ${ }^{(43)}$ included two additional studies to the five examined by Gdalevich et $a l^{(13)}$ and found a similar increased risk of approximately $37 \%$ for asthma in children that were artificially fed as infants without a family history of asthma. Potential confounders, including age, socio-economic status, family history of atopy and parental smoking, were controlled for. No significant 
Table 2 Approximate risk exposures to artificial baby milk

\begin{tabular}{lccccc}
\hline & $\begin{array}{c}\text { Low exposure (adults } \\
\text { born before 1940) }\end{array}$ & & $\begin{array}{c}\text { High exposure (adults born } \\
\text { during 1965-1975) }\end{array}$ & & $\begin{array}{c}\text { Moderate exposure (infants/children/ } \\
\text { young adults born since 1980) }\end{array}$ \\
\cline { 2 - 3 } & Age in 2010: $>70$ years & Age in 2010: 35-45 years & & Age in 2010: 0-30 years \\
\hline Exposure in early weeks of life (\%) & 5 & 30 & 30 & 20 \\
Exposure before 6 months (\%) & 40 & & 90 \\
\hline
\end{tabular}

relationship has yet been determined between the timing of weaning from breast-feeding and the prevalence of $\operatorname{asthma~}^{(43)}$.

\section{Coeliac disease}

Only one meta-analysis has examined coeliac disease and its association with infant feeding. Akobeng et al.'s ${ }^{(10)}$ analysis of six studies found that among infants who were not breast-feeding at the time when gluten was introduced into the infant's diet, the risk of coeliac disease in later life was doubled. Studies controlled for age, sex and area of residence, although socio-economic status may not be fully controlled for.

\section{Inflammatory bowel disease}

Klement et al. ${ }^{(44)}$ examined four studies (1359 infants) on Crohn's disease and ulcerative colitis, concluding that infants who were not breast-fed had an increased risk of both conditions, ranging from $30 \%$ to $49 \%$. There was little difference between crude and adjusted OR for various confounders (diarrhoeal disease during infancy, sex, age, race, birthplace, sibship size, birth order, maternal age, smoking and the use of oral contraceptives), suggesting that confounding did not significantly bias results.

\section{Childhood cancer}

Martin et $a l .{ }^{(8)}$ reviewed twenty-six studies that provided OR for at least one childhood cancer outcome. For artificially fed infants, an increased risk of all childhood cancers was determined from seven studies as $28 \%$, and of all childhood leukaemias from twelve studies as $12 \%$. The majority of childhood leukaemia is diagnosed as acute lymphocytic leukaemia and the most recent meta-analysis by Ip et al. ${ }^{(43)}$ found an increased risk of this chronic disease of $25 \%$ for infants breast-fed for $<6$ months. A dose-dependent relationship was evident ${ }^{(43,45)}$. The result accounts for known confounding variables, including socio-economic status, although biological mechanisms, including via infectious exposures, remain unclear.

\section{Population risk exposures}

Official national data on historical trends and patterns in infant feeding are lacking in Australia, with only a small number of national surveys and difficulties in comparability over time ${ }^{(46)}$. However, a variety of nationwide $^{(47-49)}$ and state surveys ${ }^{(50,51)}$ suggest that only $5 \%$ of Australian infants are exclusively breast-fed at 6 months, and only $10 \%$ receive any breast milk at 12 months. Approximately $60 \%$ of Australian infants are fully weaned from breast milk by 6 months of age ${ }^{(52)}$. Nationally, individuals in the lowest two socio-economic deciles are twice as likely as those in the top two deciles to have never been breast-fed ${ }^{(53)}$. Up to a third of indigenous Australians are never breast-fed ${ }^{(52)}$.

Long-term trends in infant feeding in Australia can be compiled from historical data sets on breastfeeding ${ }^{(54-56)}$. Victorian infant health clinic data for the period from 1927 to the present provide an important source of information on long-term trends in the rates of 'full' breast-feeding.* This is supplemented by data from Queensland available for the period 1939-1976.

On the basis of available data, the approximate exposure rates of the current Australian population of infants and children, young or middle-aged and elderly adults can be represented as in Table 2 . In the present study, we have chosen to discuss three population age cohorts with distinct exposures categorized as follows: 'low exposure' (aged adults who were born before 1940); 'moderate exposure' (current infants, children, adolescents and young adults who have been born since 1980) and 'high exposure' (adults born during 1965-1975). As shown in Fig. $1^{(57)}$ and Table 2, an exposure of $30 \%$ in infancy was experienced by current adults (aged 35-45 years) born during 1965-1975.

\section{Public bealtb significance}

Table 3 presents estimates of population-attributable proportion of chronic disease risk in Australia, assuming that $30 \%$ of the population is exposed to higher chronic disease risk due to artificial feeding in infancy.

The attributable proportion of chronic disease incidence in the current child and adult population will depend on the particular age cohort under consideration, as well as the range of possibilities regarding the critical level of exposure to artificial infant feeding. For example, if approximately $60 \%$ of infants are exposed to premature weaning from breast-feeding (a definition corresponding approximately to the proportion of Australian infants born since 1980, who were weaned from exclusive breast-feeding before 6 months of age), a range of $11-36 \%$ of chronic disease incidence might be avoided

\footnotetext{
* Full breast-feeding is defined as excluding artificial baby milk, but not excluding solid foods and drinks ${ }^{(55)}$.
} 


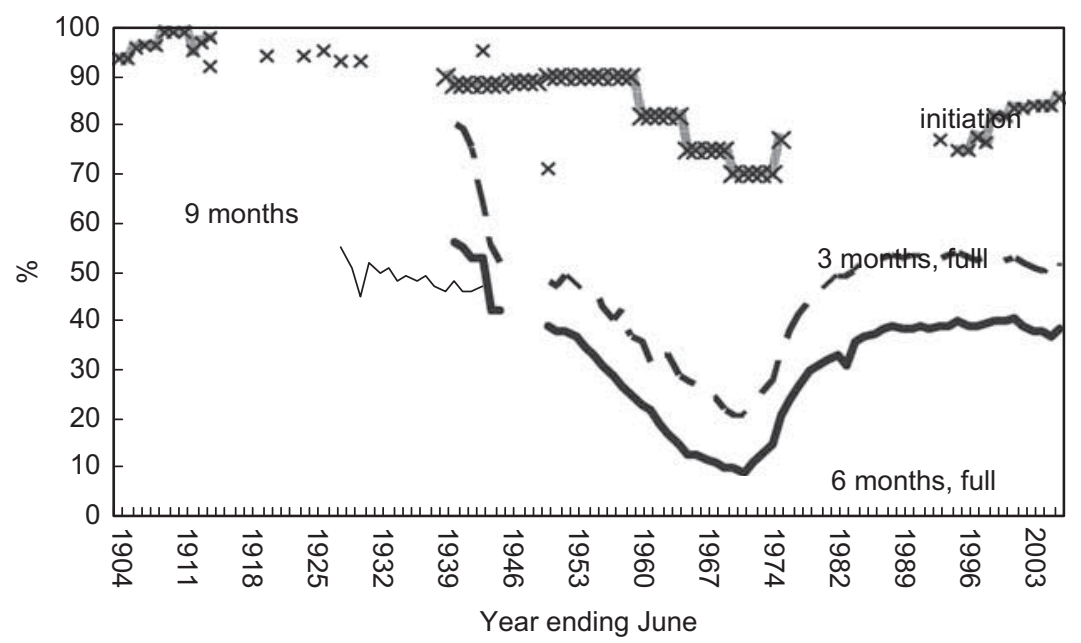

Fig. 1 Infant feeding practices in Australia during 1945-2005 (reproduced from Smith ${ }^{(57)}$ )

Table 3 Attributable proportion of chronic disease risk assuming $30 \%$ exposure

\begin{tabular}{llc}
\hline Chronic disease & RR & $\begin{array}{c}\text { Population-attributable } \\
\text { proportion (\%) }\end{array}$ \\
\hline Obesity & $1 \cdot 28$ & 8 \\
Diabetes (type 1) & $1 \cdot 43$ & 11 \\
Diabetes (type 2) & $1 \cdot 64$ & 16 \\
Heart, stroke and vascular & $1 \cdot 20$ & 6 \\
$\quad$ disease & $1 \cdot 37$ & 10 \\
Asthma & $2 \cdot 08$ & $24 \ddagger$ \\
Coeliac disease & $1 \cdot 40 \dagger$ & 11 \\
Inflammatory bowel disease & $1 \cdot 25$ & 7 \\
Childhood cancer & & \\
\hline
\end{tabular}

$\mathrm{RR}$, relative risk.

*Population-attributable proportion is calculated as $P_{\mathrm{e}}(\mathrm{RR}-1) /[1+$ $\left.P_{\mathrm{e}}(\mathrm{RR}-1)\right]$, where $P_{\mathrm{e}}$ is the prevalence of exposure to artificial feeding and $\mathrm{RR}$ is the relative risk calculated as the ratio of the incidence of morbidity in artificially fed infants to the incidence in breast-fed infants.

tThe RR ratio of 2.08 for coeliac disease is that associated with being weaned from breast-feeding before solids are introduced. We have calculated the population-attributable proportion here by assuming that $30 \%$ of infants are not being breast-fed at the time of introduction of solid food $\left(P_{\mathrm{e}}\right)$. $\ddagger A$ RR ratio of 1.40 is calculated from an average of the OR for Crohn's disease and ulcerative colitis.

through more optimal breast-feeding rates (Table 4). If breast-feeding rates were improved to Australia's National Health Target levels of around $80 \%$, i.e. an exposure reduced to $20 \%$ of the population, this intervention would reduce the attributable proportion of chronic disease in the population to a range of $4-18 \%$.

\section{Discussion}

The effect estimates from the meta-analyses above may appear small in size (e.g. the relative risk for CHD is 1.06), but they have the potential to translate into the prevention of a substantial prevalence of chronic disease in cohorts or population subgroups in which the risk exposure is $\operatorname{high}^{(21)}$.
Our analysis uses meta-analyses of risk of chronic disease to identify robust relative risk estimates from the literature. The advantage of meta-analyses is that they make available in summary form large quantities of information, which helps to establish generality and consistency of effects $^{(58)}$. Well-conducted meta-analyses can thus contribute to a more objective appraisal of epidemiological evidence and provide a more precise estimate of treatment effects $^{(59)}$. Despite their advantages as a scientific tool, however, meta-analysis of observational studies can produce spurious results if these studies are distorted by confounding or selection bias ${ }^{(21)}$. Methodological standards for assessing quality in breast-feeding research established by Bauchner et $a l^{(60)}$ and Kramer ${ }^{(61)}$ are control for important confounding variables, adequate statistical power, clear definition of 'breast-feeding' ${ }^{\text {(62,63) }}$, avoidance of detection bias and clearly defined outcome events, including information on the severity of outcome.

The meta-analyses discussed in the present study illustrate some important methodological issues in infant feeding research, which result in continuing uncertainty about the critical level of exposure and about the magnitude of the effects on chronic disease risk of artificial feeding in infancy. First, there are very few randomized control trials that compare the effects of breast-feeding $v$. artificial feeding. This is because it would be unethical to deliberately deprive infants of breast-feeding since breast-feeding is known to be important and desirable in nearly all cases. Therefore, most studies included in the meta-analyses to date are observational. It is difficult for such studies to show causation and the results can also be confounded by unobserved differences in the groups' characteristics, other than the infant feeding method, which also affect the risk of chronic disease. This difficulty is especially so if the studies are comparing later-life outcomes, when many environmental or behavioural factors could affect the outcome. 
Table 4 Attributable proportion of chronic disease risk for different scenarios or cohorts of exposure to lack of breast-feeding

\begin{tabular}{|c|c|c|c|c|c|c|c|c|c|}
\hline \multirow[b]{2}{*}{$\begin{array}{l}\text { Rate of population exposure } \\
\text { (\% 'not breast-fed') }\end{array}$} & \multicolumn{9}{|c|}{ Proportion (\%) of chronic disease in the population that is attributable to the exposure } \\
\hline & Obesity & $\begin{array}{c}\text { Type } 1 \\
\text { diabetes }\end{array}$ & $\begin{array}{c}\text { Type } 2 \\
\text { diabetes }\end{array}$ & $\begin{array}{l}\text { Heart, stroke and } \\
\text { vascular disease }\end{array}$ & Asthma & Coeliac* & IBD & $\begin{array}{l}\text { Childhood } \\
\text { cancer }\end{array}$ & $\begin{array}{l}\text { Range for } \\
\text { all conditions }\end{array}$ \\
\hline 90 & 20 & 28 & 37 & 15 & 25 & 48 & 26 & 18 & $15-48$ \\
\hline 60 & 14 & 21 & 28 & 11 & 18 & 36 & 19 & 13 & $11-36$ \\
\hline 40 & 10 & 15 & 20 & 7 & 13 & 30 & 14 & 9 & $7-30$ \\
\hline 30 & 8 & 11 & 16 & 6 & 10 & 24 & 11 & 7 & $6-24$ \\
\hline 20 & 5 & 8 & 11 & 4 & 7 & 18 & 7 & 5 & $4-18$ \\
\hline 10 & 3 & 4 & 6 & 2 & 4 & 10 & 4 & 2 & $2-10$ \\
\hline
\end{tabular}

$\mathrm{IBD}$, inflammatory bowel disease; $\mathrm{RR}$, relative risk.

${ }^{*}$ The RR ratio of 2.08 for coeliac disease is that associated with being weaned from breast-feeding before solids are introduced. We have calculated this figure for coeliac disease by assuming that the exposure $\left(P_{\mathrm{e}}\right)$ is not being breast-fed at the time of introduction of solid food $\left(P_{\mathrm{e}}\right)$.

It is also important to consider whether the study is large enough to show an effect. Many studies on infant feeding are small in scale and have too few infants who are exclusively breast-fed or exclusively artificially fed for the study to have adequate statistical power to confirm differences between the infant feeding methods. When there are also problems in how the feeding groups are defined, small studies showing no difference between feeding groups are even more unreliable.

The inconsistent or inappropriate definitions of breastfeeding introduce a significant lack of precision that is a major problem in existing breast-feeding research ${ }^{(62)}$. For example, in the meta-analyses reviewed in the present study, the infant feeding categories were highly diverse. Artificially fed groups included infants fed cow's milk, standard formula, preterm formula, fatty acid supplemented formula or breast-fed for $x$ number of days/ weeks/months only. Similarly, 'breast-fed' was variously defined as ever breast-fed, breast-fed for more than $x$ number of days/weeks/months or exclusively breast-fed for more than $x$ number of days/weeks/months. Artificially fed infants were more often misclassified as breast-fed. The most common classification in the studies included in the meta-analyses was 'ever' $v$. 'never' breast-fed. For example, a study of childhood cancer states that 'in $92 \%$ of reviewed studies, measurement of exposure was limited to whether the child had ever or never been breastfed $^{(8)}$. Therefore, there is a likely understatement of the effect of infant feeding due to non-random misclassification. This will affect both statistical significance and effect sizes in such studies. Indeed, most studies wrongly conceptualize breast-fed infants as the exposed or intervention group, rather than characterizing artificial feeding as the exposure ${ }^{(64)}$.

Risk exposure is admittedly difficult to define in the area of infant feeding. Definitions that are suitable for monitoring and surveillance of breast-feeding trends may not be optimal for clinical or epidemiological research ${ }^{(62,65)}$. For some conditions, a single exposure to artificial feeding in early infancy may be expected to trigger increased risk of chronic disease $^{(66)}$, but for other conditions with a different aetiology, different health outcomes are expected from varying durations of exposure over several weeks or months. The greater effect size we observed in studies with more precise measurement of duration or intensity of exposure to artificial feeding suggests that pooled estimates from metaanalyses, which include studies with ambiguous measures of exposure and inadequate specification of the different feeding groups, may understate the magnitude of the effects of early infant feeding on chronic disease in later life.

It also noteworthy that the findings of consistent reductions in risk for breast-fed infants across many longterm health outcomes are based on data for populations exposed to a variety of environmental contaminants during their infancy and adult life. The present study includes a broad range of outcomes and is important in providing a balanced perspective on this issue. The common practice of accurately measuring exposures to environmental pollution via the convenient, non-invasive testing of collected breast milk may confuse and distort the perspectives on risks and infant feeding by wrongly inferring that breast milk (the 'messenger') rather than environmental pollution is the health risk, or that formula feeding involves no health risks ${ }^{(67)}$. Neurotoxic effects have rarely been linked to exposure during infancy or childhood $^{(68)}$ and in virtually all studies, beneficial effects of breast-feeding outweigh any potential adverse effect of milk organochlorine contaminants ${ }^{(69)}$. Lower weight gain of breast-fed infants is presented in some studies ${ }^{(35)}$ as evidence of harm from postnatal exposure, but such an interpretation is at odds with concerns about adverse early growth implications for later risk of obesity in nonbreast-fed infants ${ }^{(70)}$. Such an interpretation also contrasts with the paradigm underlying new WHO growth charts that establish breast-fed, not formula-fed, infant growth patterns as the biological norm ${ }^{(71)}$.

\section{Mechanisms}

Our analysis uses relative risk estimates from the metaanalyses of studies that are mainly observational rather than experimental. As noted earlier, it is difficult for observational studies to show 'causation'. Experimental studies of animals may also contribute to an understanding of these mechanisms. Findings are more conclusive if there is 


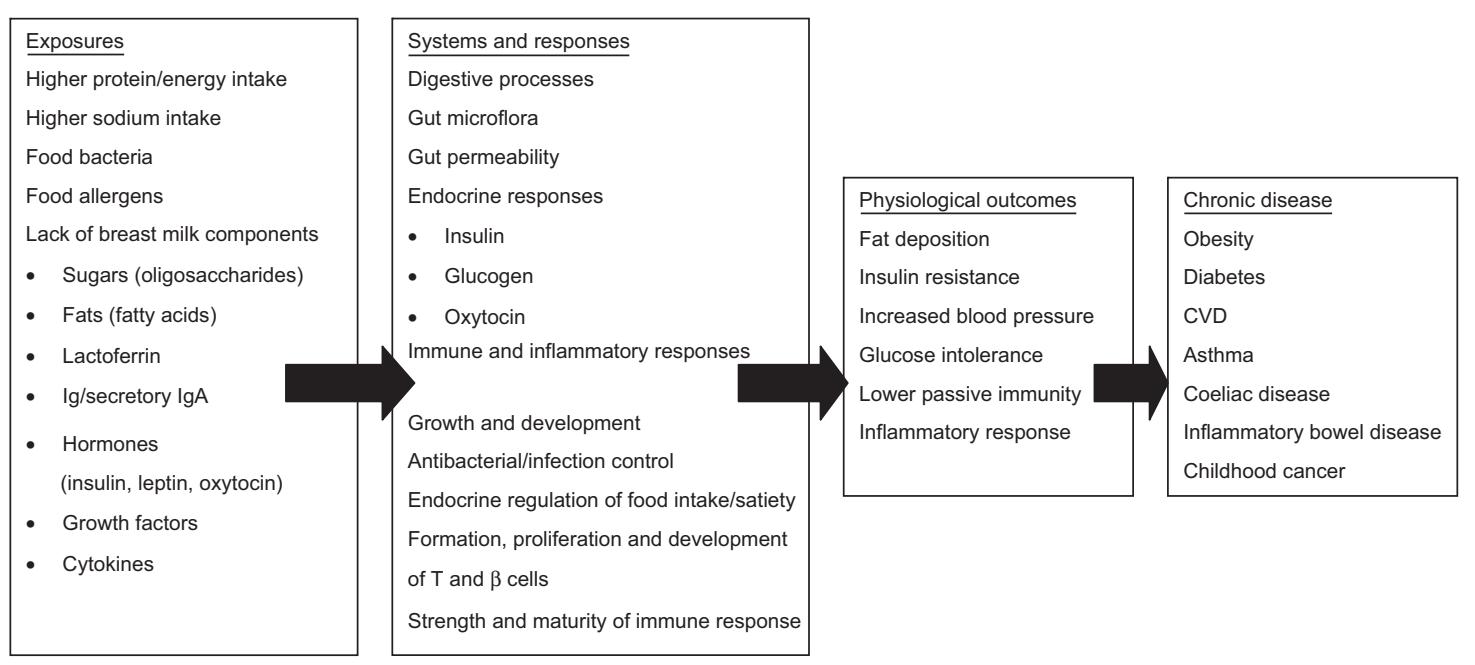

Fig. 2 Conceptual pathway for underlying chronic disease risk in artificially fed infants

a dose-dependent relationship, i.e. if earlier or more complete artificial feeding shows larger differences or effects than when artificial baby milk is introduced later, or when artificial baby milk is combined with breast-feeding. A number of studies have found a dose response of various chronic diseases to artificial feeding in early life as noted above in our review of the meta-analyses.

Findings are also more persuasive if there are biologically plausible ways in which an 'exposure' (such as artificial feeding) could result in a higher incidence of a subsequent condition or disease. The aetiology of many of the chronic diseases examined here is multifactorial. Both genetic susceptibility and environmental factors play a significant role in the development of asthma ${ }^{(72)}$, childhood cancer ${ }^{(73)}$, type 1 diabetes $^{(74)}$ and inflammatory bowel disease ${ }^{(44)}$. It is still unclear how artificial feeding exerts its effect as an environmental factor. The compositional differences between breast milk and artificial baby milk are likely to be important as are the complex metabolic programming effects of human milk ${ }^{(75-77)}$. There is growing evidence that diet in infancy has short- and long-term effects on how the body metabolizes food, as well as influencing food intake levels and composition $^{(75,78-81)}$. In some cases, early feeding practices that affect later feeding or eating behaviours may also play a role $\mathrm{e}^{(43,76)}$.

Figure 2 details a conceptual pathway for chronic risk of disease in artificially fed infants. Different exposures to nutrients and bioactive factors, either present in breast milk or absent in artificial baby milk, may lead to a number of different responses or the abnormal development of regulatory processes. These systems and responses, in turn, produce undesirable physiological outcomes and eventual development of chronic disease.

The components in breast milk (including a complex and dynamic mix of nutrients, hormones, growth factors and cytokines) play a key role in developing body systems to appropriately regulate food intake, process fats and sugars, and influence body weight and infant growth ${ }^{(82-91)}$. A higher energy intake by artificially fed infants leads to a higher body weight gain during the critical neonatal period compared with breast-fed infants ${ }^{(79,92)}$. Such growth acceleration in early infancy has been linked to 'malprogramming' and a lasting increased risk of obesity, diabetes and $\operatorname{CVD}^{(76,78,81,82,91,93)}$. Lower levels of sodium in breast milk are thought to provide a plausible explanation for reduced blood pressure in later life ${ }^{(8)}$.

Various complex and interrelated components in human breast milk are not replicated in artificial baby milk. For example, the long-chain PUFA found in breast milk may play a crucial role in energy metabolism, as they are a source of energy; in blood pressure control, since they are important structural components of tissue membrane systems, including the vascular endothelium; and in molecular signalling, with the synthesis of prostaglandins and leucotrienes ${ }^{(72,94)}$. These fatty acids are also inversely correlated to fasting glucose levels and disruption of these levels may lead to changes in the skeletal muscle membrane, increased fasting glucose levels and too much insulin in the blood, eventual $\beta$-cell failure and diabetes ${ }^{(38)}$. Another hormone found in breast milk, leptin, has been found to exert a protective effect against excessive infant weight gain ${ }^{(87)}$, via appetite suppression and regulation of energy intake ${ }^{(86)}$. Artificially fed infants, however, are thought to develop resistance to leptin, leaving them at risk of excess weight gain ${ }^{(86)}$.

In addition to lowering blood pressure and reducing the risk of $\mathrm{CVD}^{(95)}$, hormones contained within breast milk also promote the functional maturity of the intestinal mucosal tissues. Such mucosal defences are important in protection from infection and may limit the development of diabetes $^{(74)}$, asthma ${ }^{(96)}$, inflammatory bowel disease ${ }^{(97)}$ and coeliac disease $^{(10)}$ in susceptible individuals. The mode of feeding can also influence the levels of the hormone insulin. 
Artificial feeding has been linked to increased plasma insulin levels, possibly as a result of higher protein intakes, and the later development of obesity and diabetes ${ }^{(77)}$ due to greater fat deposition and development of adipocytes ${ }^{(98)}$. Such altered levels of insulin may also lead to insulin resistance, which is thought to be associated with increased blood pressure $^{(94)}$.

Breast milk has anti-microbial, anti-inflammatory and immunomodulatory properties due, in part, to the cytokines, hormones and growth factors present. The immunomodulatory properties of human breast milk (via passive immunity, a T-cell-specific suppressive effect or diminished immune responses) may confer protection against postnatal antigenic exposures and the subsequent development of type 1 diabetes ${ }^{(40)}$, childhood cancer ${ }^{(8,99)}$, asthma $^{(39)}$, coeliac disease $^{(10)}$ and inflammatory bowel disease ${ }^{(44)}$. Indeed, the protection afforded by breast milk may also be due to delayed exposure to harmful bacteria or foreign food antigens that may be otherwise present in artificial milk ${ }^{(100)}$.

Finally, different feeding behaviours may play a role in chronic disease development, e.g. suckling patterns, and the infant's degree of control over meal sizes and feeding intervals are altered in artificially fed as compared with breast-fed infants ${ }^{(101-103)}$. Intake of artificial baby milk is determined by the mother, whereas breast-feeding facilitates development of an infant's self-control ${ }^{(76,103)}$. Later food preferences may then tend towards healthy eating and better nutrition, since components of human milk and the suckling experience affect feeding behaviours and preferences of the mother and/or the child ${ }^{(94,102-105)}$.

\section{Conclusion}

There are many uncertainties about the links between nutrition in infancy and risk of chronic disease in later life due to the methodological flaws in existing research. These flaws would most likely work in the direction of understating the effect on the risk of chronic diseases from artificial feeding in the context of how breast-feeding is defined. Conversely, the risks may be overstated if residual confounding is not adequately accounted for. Overall, we suggest that poor measurement of breastfeeding lowers the measured effects in these studies at least as much as inadequate control for relevant confounding does. Confidence in many studies is also weakened by their small sample sizes. High-quality studies (such as those with large sample sizes, clear comparisons of substantially breast-fed and substantially artificially fed infants, and appropriate adjustment for confounding variables) are more likely to find an association between lack of breast-feeding in infancy and increased incidence of chronic diseases in later life.

While conclusive evidence is still lacking because of flawed research design and ethical barriers to randomized control trials, a wide range of biological, animal and epidemiological studies and some randomized control trials point to a small but consistent effect of exclusive artificial feeding in infancy in increasing the risk of chronic disease in later life. The relationship appears to be dose-dependent, with larger positive effects on the risk of disease associated with more exclusive or longer duration of breast-feeding.

While the clinical effect sizes are relatively small (with relative risks of chronic disease ranging from $1 \cdot 2$ to $2 \cdot 1$ ), the risk of exposure in a developed country population such as Australia is substantial. Approximately $90 \%$ of current 35-45-year-olds were weaned from breast milk before they reached 6 months of age. Around 20-60\% of current Australian infants, especially those in low socioeconomic groups, are still exposed to heightened levels of risk of chronic disease in later life due to weaning from breast-feeding either as newborns or before 6 months. These large population-level exposures to artificial baby milk suggest that infant feeding practices may not only contribute importantly to explaining current levels of chronic disease in current middle-aged adults, but also provide a potential avenue for reducing future chronic disease burden and health system costs.

Despite the uncertainties, we suggest that there is enough evidence to show that breast-feeding affects chronic disease incidence at the population level and is, therefore, of significance to public health policy. Although the average effects are modest, widespread population exposure to premature weaning means that relatively small effects from improving breast-feeding rates have a potentially large impact on population health.

Our findings have potentially significant economic implications. Health system cost impacts of premature weaning on common childhood and infectious illnesses are reasonably well documented. Several studies have identified substantial short-term health system, hospital or health fund cost savings from reducing premature weaning and associated infections, such as gastrointestinal illness or respiratory illness ${ }^{(106-108)}$.

Many interventions currently proposed to reduce obesity and related chronic illnesses are expensive, but are not sustained and are, therefore, not cost-effective. Breast-feeding can be considered to be a one-off 'intervention' that continues to reduce risk of chronic disease throughout the life cycle. Unlike other interventions, such as exercise programmes or dietary changes, it does not have to be continued throughout the life cycle in order to maintain this protection and, therefore, has no ongoing costs. There are few other preventive health interventions that have proven to be permanently effective in reducing risk factors for chronic disease or chronic disease in a variety of settings.

With these lasting effects over the long term ${ }^{(78)}$, breastfeeding is likely to be cost effective as a disease prevention measure. It is crucial, nevertheless, that public health advocacy addresses significant workplace and cultural 
barriers to breast-feeding to avoid breast-feeding promotion imposing economic and other costs on women ${ }^{(23,109)}$. Further research is needed to quantify these costs and cost savings, but meanwhile, it would seem that implementing cost-effective interventions to support breast-feeding could be an important element of strategies to restrain future escalation of health costs of chronic disease burdens.

\section{Acknowledgements}

Funding for the project and fellowship to J.P.S. came from the Australian Research Council. The authors have no conflict of interest to declare. Each author contributed to implementation of the study, data collection and analysis and writing of the manuscript. J.P.S. was responsible for study design and wrote the first draft of the manuscript. Each author has seen and approved the contents of the manuscript. The present manuscript is an original work and has not been published previously. It is not currently being considered by any other journal and, if accepted by Public Health Nutrition, it will not be published elsewhere in the same form, in English or in any other language, without the written consent of the Nutrition Society.

\section{References}

1. World Health Organization (2003) Diet, Nutrition and the Prevention of Chronic Diseases. Joint WHO/FAO Expert Consultation. WHO Technical Report Series no. 916. Geneva: WHO.

2. World Health Organization (2000) Obesity: Preventing and Managing the Global Epidemic. WHO Technical Report Series no. 894. Geneva: WHO.

3. Gartner L, Morton J, Lawrence R et al. (2005) Breastfeeding and the use of human milk. Pediatrics 115, 496-506.

4. Arenz S, Ruckerl R, Koletzko B et al. (2004) Breast-feeding and childhood obesity - a systematic review. Int $J$ Obes Relat Metab Disord 28, 1247-1256.

5. Owen C, Martin R, Whincup P et al. (2005) Effect of infant feeding on the risk of obesity across the life course: a quantitative review of published evidence. Pediatrics $\mathbf{1 1 5}$, $1367-1377$.

6. Owen CG, Martin RM, Whincup PH et al. (2006) Does breastfeeding influence risk of type 2 diabetes in later life? A quantitative analysis of published evidence. Am J Clin Nutr 84, 1043-1054.

7. Martin R, Gunnell D \& Davey Smith G (2005) Breastfeeding in infancy and blood pressure in later life: systematic review and meta analysis. Am J Epidemiol 161, 15-26.

8. Martin R, Gunnell D, Owen C et al. (2005) Breast-feeding and childhood cancer: a systematic review with metaanalysis. Int J Cancer 117, 1020-1031.

9. Collaborative Group on Hormonal Factors in Breast Cancer (2002) Breast cancer and breastfeeding: collaborative reanalysis of individual data from 47 epidemiological studies in 30 countries, including 50302 women with breast cancer and 96973 women without the disease. Lancet $\mathbf{3 6 0}$, 187-195.

10. Akobeng A, Ramanan A, Buchan I et al. (2006) Effect of breast feeding on risk of coeliac disease: a systematic review and meta-analysis of observational studies. Arch Dis Child 91, 39-43.
11. Klement E \& Reif S (2005) Breastfeeding and risk of inflammatory bowel disease. Am J Clin Nutr 82, 486.

12. Gdalevich M, Mimouni D, David M et al. (2001) Breastfeeding and the onset of atopic dermatitis in childhood: a systematic review and meta-analysis of prospective studies. J Am Acad Dermatol 45, 520-527.

13. Gdalevich M, Mimouni D \& Mimouni M (2001) Breastfeeding and the risk of bronchial asthma in childhood: a systematic review with meta-analysis of prospective studies. J Pediatr 139, 261-266.

14. Oddy W (2005) A review of the effects of breastfeeding on respiratory infections, atopy, and childhood asthma. J Asthma 41, 605-621.

15. World Health Organization (2006) The Challenge of Obesity in the WHO European Region and the Strategies for Response. Copenhagen: WHO Regional Office for Europe.

16. World Health Organization (2006) European Charter on Counteracting Obesity. Copenhagen: WHO Regional Office for Europe.

17. World Cancer Research Fund, American Institute for Cancer Research (2007) Food, Nutrition, Physical Activity, and the Prevention of Cancer: A Global Perspective. Washington, DC: AICR.

18. National Health Priority Action Council (2005) National Chronic Disease Strategy. Canberra: Australian Government Department of Health and Ageing.

19. World Health Assembly (2001) Infant and Young Child Nutrition. Resolution 54.2. Geneva: WHO.

20. Australian Bureau of Statistics (2003) Breastfeeding in Australia, 2001. Catalogue no. 4810.0.55.001. Canberra: ABS.

21. Egger M, Schneider M \& Davey Smith G (1998) Spurious precision? Meta-analysis of observational studies. BMJ 316, 140-144.

22. Baxter J \& Smith JP (2009) Breastfeeding and Infants' Time Use. Research Paper no. 43. Melbourne: Australian Institute of Family Studies.

23. Smith J \& Ellwood M (2007) Who pays for the health benefits of breastfeeding? An analysis of time costs. Presented at Public Health Association of Australia National Annual Conference, Alice Springs, 23-26 September.

24. Cooklin AR, Donath SM \& Amir LH (2008) Maternal employment and breastfeeding: results from the longitudinal study of Australian children. Acta Paediatr 97, 620-623.

25. Hawkins SS, Griffiths LJ \& Dezateux C (2007) The impact of maternal employment on breast-feeding duration in the UK Millennium Cohort Study. Public Health Nutr 10, 891-896.

26. Ryan AS, Zhou W \& Arensberg MB (2005) The effect of employment status on breastfeeding in the United States. Womens Health Issues 2006, 243-251.

27. Hausman BL (2003) Mother's Milk: Breastfeeding Controversies in American Culture. London: Routledge.

28. Gatrell CJ (2007) Secrets and lies: breastfeeding and professional paid work. Soc Sci Med 65, 393-404.

29. Rippeyoung PLF (2009) Feeding the state: breastfeeding and women's well-being in context. J Assoc Res Mothering 11, 36-48.

30. Hausman BL (2000) Rational management: Medical authority and ideological conflict in Ruth Lawrence's breastfeeding: a guide for the medical profession. Tech Comm Q 9, 271-289.

31. Smith R (2010) Breastmilk no better for baby than formula, scientist claims. The Telegraph, 6 January; available at http:// www.telegraph.co.uk/healthnews/6942427/Breastmilkno-better-for-baby-than-formula-scientist-claims.html

32. British Broadcasting Corporation (2010) Hormones 'Govern Ability to Breastfeed'. http://www.news.bbc.co.uk/2/hi/ health/8443904.stm 
33. UNICEF UK (2010) UNICEF UK Baby Friendly Initiative statement on new breastfeeding research. http://www. babyfriendly.org.uk/items/item_detail.asp?item $=620$

34. Eggesbø M, Stigum H \& Longnecker MP (2009) Levels of hexachlorobenzene (HCB) in breast milk in relation to birth weight in a Norwegian cohort. Environ Res 109, 559-566.

35. Grandjean P, Budtz-Jorgensen E, Steuerwald U et al. (2004) Breastfeeding and the weanling's dilemma. Am J Public Health 94, 1075-1076.

36. Stein CR, Savitz DA \& Dougan M (2009) Serum levels of perfluorooctanoic acid and perfluorooctane sulfonate and pregnancy outcome. Am J Epidemiol 170, 837-846.

37. Harder T, Bergmann R, Kallischnigg G et al. (2005) Duration of breastfeeding and risk of overweight: a metaanalysis. Am J Epidemiol 162, 397-403.

38. Horta B, Bahl R, Martines J et al. (2007) Evidence of the Long-term Effects of Breastfeeding: Systematic Reviews and Meta-analysis. Geneva: WHO.

39. van Rossum C, Buchner F \& Hoekstra J (2005) Quantification of Health Effects of Breastfeeding. Review of the Literature and Model Simulation. Bilthoven: RIVM.

40. Gerstein H (1994) Cow's milk exposure and type I diabetes mellitus. A critical overview of the clinical literature. Diabetes Care 17, 13-19.

41. Norris J \& Scott F (1996) A meta-analysis of infant diet and insulin-dependent diabetes mellitus: do biases play a role? Epidemiology 7, 87-92.

42. Owen CG, Whincup PH, Gilg JA et al. (2003) Effect of breast feeding in infancy on blood pressure in later life: systematic review and meta-analysis. BMJ 327, 1189-1195.

43. Ip S, Chung M, Raman G et al. (2007) Breastfeeding and Maternal and Infant Health Outcomes in Developed Countries. Evidence Report/Technology Assessment no. 153. Rockville, MD: Agency for Healthcare Research and Quality.

44. Klement E, Cohen R, Boxman J et al. (2004) Breastfeeding and risk of inflammatory bowel disease: a systematic review with meta-analysis. Am J Clin Nutr 80, 1342-1352.

45. Kwan M, Buffler P, Abrams B et al. (2004) Breastfeeding and the risk of childhood leukemia: a meta-analysis. Public Health Rep 119, 521-535.

46. House of Representatives Standing Committee on Health and Aging (2007) The Best Start. Report on the Inquiry into the Health Benefits of Breastfeeding. Canberra: Commonwealth of Australia.

47. Australian Bureau of Statistics (2003) Breastfeeding in Australia. Catalogue no. 4810.0.55.001. Canberra: ABS.

48. Donath S \& Amir LH (2000) Rates of breastfeeding in Australia by State and socio-economic status: evidence from the 1995 National Health Survey. J Paediatr Child Health 36, 164-168.

49. National Health and Medical Research Council (2003) Dietary Guidelines for Children and Adolescents in Australia Incorporating the Infant Feeding Guidelines for Health Workers. Canberra: NHMRC.

50. Gabriel R, Pollard G, Suleman G et al. (2005) Infant and Child Nutrition in Queensland 2003. Brisbane: Queensland Health.

51. Hector D, Webb K \& Lymer S (2005) Report on Breastfeeding in NSW 2004 (revised). Sydney: NSW Department of Health.

52. Hector D, Webb K \& Lymer S (2005) State of Food and Nutrition in NSW Series: Report on Breastfeeding in NSW 2004. Sydney: NSW Department of Health.

53. Australian Institute of Health and Welfare (2003) Australia's Welfare 2003. Canberra: AIHW.

54. Mein-Smith P (1991) Infant welfare services and infant mortality. Aust Econom Rev 24, 22-34.
55. Mortenson K (2001) Australian Breastfeeding Statistics. Lactation Resource Centre Hot Topics. Melbourne: Australian Breastfeeding Association.

56. Siskind V, Del-Mar C \& Schofield F (1993) Infant feeding in Queensland, Australia: long term trends. Am J Public Health 83, 103-106.

57. Smith JP (2007) The contribution of infant food marketing to the obesogenic environment in Australia. Breastfeed Rev 15, 23-35.

58. Mulrow C (1994) Systematic reviews: rationale for systematic reviews. BMJ 309, 597-599.

59. Egger M \& Smith GD (1997) Meta-analysis: potentials and promise. BMJ 315, 1371-1374.

60. Bauchner H, Leventhal J \& Shapiro E (1986) Studies of breast-feeding and infections. How good is the evidence? JAMA 256, 887-892.

61. Kramer M (1988) Does breastfeeding help protect against atopic disease? Biology, methodology, and a golden jubilee of controversy. J Pediatr 112, 181-190.

62. Labbok M \& Krasovec K (1990) Toward consistency in breastfeeding definitions. Stud Fam Plann 21, 226-230.

63. Heinig M (2001) Host defense benefits of breastfeeding for the infant effect of breastfeeding duration and exclusivity. Pediatr Clin North Am 48, 105-123.

64. Smith J, Dunstone M \& Elliott-Rudder M (2009) Health professional knowledge of breastfeeding: are the health risks of infant formula feeding accurately conveyed by the titles and abstracts of journal articles? J Hum Lact 25, 350-358.

65. Webb K, Marks G, Lund-Adams M et al. (2001) Towards a National System for Monitoring Breastfeeding in Australia: A Discussion Paper. Canberra: Commonwealth Department of Health and Aged Care.

66. Host A (1991) Importance of the first meal on the development of cow's milk allergy and intolerance. Allergy Proc 12, 227-232.

67. Van Esterik P (2006) Risks, Rights and Regulation. Communicating about Risks and Infant Feeding. Toronto: National Network on Environments and Women's Health.

68. Jacobson JL \& Jacobson SW (2001) Postnatal exposure to PCBs and childhood development. Lancet $\mathbf{3 5 8}$, 1568-1569.

69. Korrick SA \& Sagiv SK (2008) Polychlorinated biphenyls, organochlorine pesticides and neurodevelopment. Curr Opin Pediatr 20, 198-204.

70. Gunnarsdottir I, Schack-Nielsen L, Michaelsen KF et al. (2009) Infant weight gain, duration of exclusive breastfeeding and childhood BMI - two similar follow-up cohorts. Public Health Nutr 13, 201-207.

71. De Onis M, Onyango AW, Borghi E et al. (2006) Comparison of the World Health Organization (WHO) child growth standards and the National Center for Health Statistics/WHO international growth reference: implications for child health programmes. Public Health Nutr $\mathbf{9}$, 942-947.

72. Warner J (2007) Early life nutrition and allergy. Early Hum Dev 83, 777-783.

73. Ortega-Garcia J, Ferris-Tortajada J, Torres-Cantero A et al. (2008) Full breastfeeding and paediatric cancer. J Paediatr Child Health 44, 10-13.

74. Peng H \& Hagopian W (2006) Environmental factors in the development of type 1 diabetes. Rev Endocr Metab Disord 7, 149-162.

75. Dietz W (2001) Breastfeeding may help prevent childhood overweight. JAMA 285, 2506-2507.

76. Gillman M, Rifas-Shiman S, Camargo J et al. (2001) Risk of overweight among adolescents who were breastfed as infants. JAMA 285, 2461-2467.

77. Dewey K (2003) Is breastfeeding protective against child obesity? J Hum Lact 19, 9-18. 
78. Plagemann A \& Harder T (2005) Breast feeding and the risk of obesity and related metabolic diseases in the child. Metab Syndr Relat Disord 3, 222-232.

79. Heinig M, Nommsen L, Peerson J et al. (1993) Energy and protein intakes of breast-fed and formula-fed infants during the first year of life and their association with growth velocity: the DARLING Study. Am J Clin Nutr 58, 152-161.

80. Lucas A (1998) Programming by early nutrition: an experimental approach. J Nutr 128, 401-406.

81. Singhal A \& Lucas A (2004) Early origins of cardiovascular disease: is there a unifying hypothesis? Lancet $\mathbf{3 6 3}$, $1642-1645$.

82. Weaver L (2006) Rapid growth in infancy: balancing the interests of the child. J Pediatr Gastroenterol Nutr 43, 428-432.

83. Hamosh M (2001) Bioactive factors in human milk. Pediatr Clin North Am 48, 69-86.

84. Hauner H, Rohrig K \& Petruschke T (1995) Effects of epidermal growth factor (EGF), platelet-derived growth factor (PDGF) and fibroblast growth factor (FGF) on human adipocyte development and function. Eur J Clin Invest 25, 90-96.

85. Koletzko B, Agostoni C, Carlson S et al. (2001) Long chain polyunsaturated fatty acids (LCPUFA) and perinatal development. Acta Paediatr 90, 460-464.

86. Singhal A, Farooqi I, O'Rahilly S et al. (2002) Early nutrition and leptin concentrations in later life. Am J Clin Nutr 75, 993-999.

87. Miralles O, Sanchez J, Palou A et al. (2006) A physiological role of breast milk leptin in body weight control in developing infants. Obes Res 14, 1371-1377.

88. Ailhaud G \& Guesnet P (2004) Fatty acid composition of fats is an early determinant of childhood obesity: a short review and an opinion. Obes Res 5, 21-26.

89. Ailhaud G, Massiera F, Weill P et al. (2006) Temporal changes in dietary fats: role of $n-6$ polyunsaturated fatty acids in excessive adipose tissue development and relationship to obesity. Prog Lipid Res 45, 203-236.

90. Agostoni C (2005) Small-for-gestational-age infants need dietary quality more than quantity for their development: the role of human milk. Acta Paediatr 94, 827-829.

91. Singhal A (2006) Early nutrition and long-term cardiovascular health. Nutr Rev 64, 44-49.

92. Baker J, Michaelsen K, Rasmussen K et al. (2004) Maternal prepregnant body mass index, duration of breastfeeding, and timing of complementary food introduction are associated with infant weight gain. Am J Clin Nutr 80, 1579-1588.

93. Stettler N, Zemel B, Kumanyika S et al. (2002) Infant weight gain and childhood overweight status in a multicenter, cohort study. Pediatrics 109, 1259-1266.
94. Martin RM, Ness AR, Gunnell D et al. (2004) Does breastfeeding in infancy lower blood pressure in childhood? Circulation 109, 1259-1266.

95. Lawlor D, Riddoch C, Page A et al. (2005) Infant feeding and components of the metabolic syndrome: findings from the European Youth Heart Study. Arch Dis Child 90, 582-588.

96. van Rossum C, Buchner FL \& Hoekstra J (2006) Quantification of Health Effects of Breastfeeding. Netherlands: Centre for Nutrition and Health.

97. Whorwell P, Holdstock G, Whorwell G et al. (1979) Bottle feeding, early gastroenteritis, and inflammatory bowel disease. BMJ 1, 382.

98. von Kries R, Koletzko B, Sauerwald T et al. (1999) Breast feeding and obesity: cross sectional study. BMJ 319, 147-150.

99. Greaves M (1997) Aetiology of acute leukaemia. Lancet 349, 344-349.

100. Virtanen S \& Knip M (2003) Nutritional risk predictors of cell autoimmunity and type 1 diabetes at a young age. $\mathrm{Am}$ J Clin Nutr 78, 1053-1067.

101. Agras W, Kraemer H, Berkowitz R et al. (1987) Does a vigorous feeding style influence early development of adiposity? J Pediatr 110, 799-804.

102. Birch L \& Fisher J (1998) Development of eating behaviors among children and adolescents. Pediatrics 101, Suppl. 3, 539-549.

103. Ventura A, Savage J, May A et al. (2005) Early behavioural, familial and psychosocial predictors of overweight and obesity. In Encyclopedia on Early Childhood Development, pp. 1-20 [RE Tremblay, RG Barr \& RDeV Peters, editors]. Montreal, Quebec: Centre of Excellence for Early Childhood Development; available at http://www. child-encyclopedia.com/documents/Ventura-Savage-MayBirchANGxp.pdf/

104. Taveras E, Scanlon K, Birch L et al. (2004) Association of breastfeeding with maternal control of infant feeding at age 1 year. Pediatrics 114, e577-e 583.

105. Sullivan S \& Birch L (1994) Infant dietary experience and acceptance of solid foods. Pediatrics 93, 271-277.

106. Weimer J (2001) The Economic Benefits of Breastfeeding: A Review and Analysis. Washington, DC: USDA.

107. Drane D (1997) Breastfeeding and formula feeding: a preliminary economic analysis. Breastfeed Rev 5, 7-16.

108. Smith JP, Thompson JF \& Ellwood DA (2002) Hospital system costs of artificial infant feeding: estimates for the Australian capital territory. Aust NZ J Public Health 26, 543-551.

109. Smith JP (2004) Mothers' milk and markets. Aust Fem Stud 19, 369-379. 